TITLE: RADLATION-INDUCED ATTENUATION OF HIGH-OH OPTICAL FIBERS

AFTER HYDROGEN TREATMENT IN THE PRESENCE OF IONIZING RADIATION

AUTHOR(S): Peter B. Lyons and Larry D. Looney

\author{
SUBMITTEO TO: RADECS 91 \\ Montpellier - FRANCE \\ September $9-12,1991$
}

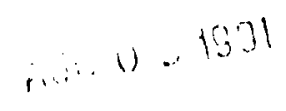

\title{
DISC LAIMER
}

\begin{abstract}
Thas report was prepured is an account of work sponsored by an agency of the / Inited Sitates Government. Neither the Inited States (jovernment nor any agency thereof, nur any of their employees, makes any warranty, express or implied, or assumes any lepal liability or resposnsi. bility for the accuracy. completeness, or usefulness of any information, apparatus, product, or process disclised, or represents that its use would not infringe privately owned rights Kefer. ence herein (1) any specific commercial proxluc, proxess, or service by trade name, trademark. manufacturer, of otherwise dies mot necessarily constitute or imply its endorsement, recom. mendation, of favering by the linited Stites finvernment or any agency thereof The views

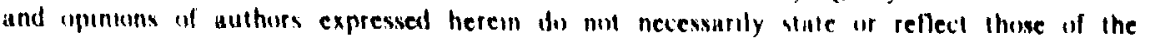
I Inied Sitates (iovernment of any agency thereof
\end{abstract}

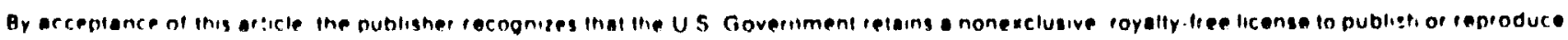

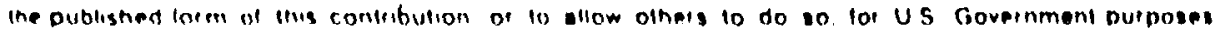

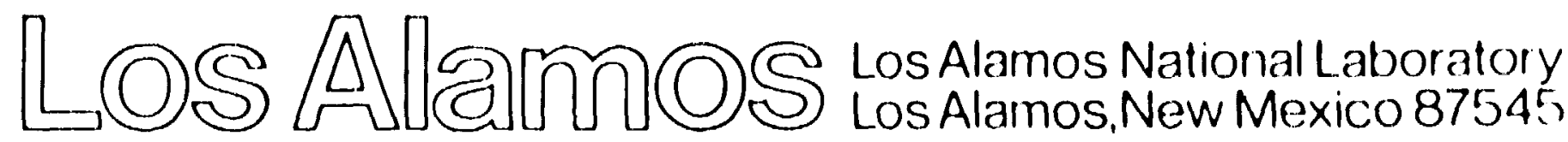




\title{
Kadiation-Induced Attenuation of High-OH Optical Fibers After Hydrogen Treatment in the Presence of Ionizing Radiation
}

\author{
P. B. Lyons and L. D. Looney 1 \\ Los Alamos National Laborntory \\ Los Alamos, New Mexico, 87545 \\ Telephone 505-667-3899 \\ FAX 505-667-0407
}

\begin{abstract}
High purity, high.OH, optlcal flbers were irradiated lo a hydrogen atmosphere to explore bydrogen binding lato defects created by the lonizing radiation. Signiflcant improvements in subsequent measurements of radiatlon-laduced attenuation were observed.
\end{abstract}

\section{INTRODUCTION}

For more than two decades, hydrogen has been identified as a significant factor in controlling the performance of silica materials. Early experiments [1,2] demonstrated that radiation-induced attenuation in bulk silica ramples was reduced if hydrogen was impregnaied into the materials. Some of the earliest observations of hydrogen effects in fibers involved the ease by which molecular hydrogen could diffuse through the small dimensions of optical fibers, coupled with concerns and measurements demonstrating that increases in hydregen concentration within the fiber core could lead to increased attenuation at certain wavelengths [3]. A number of papers considered the importance of fiber cabling designed 10 minimize the generation of hydrogen in proximity to the fibers [4,5], especially in very long distance undersea applications of optical fibers. These concerns also encouraged development of a range of technologies to hermetically seal the surface of optical fibers 10 significantly reduce diffusion of hydrogen into the silica material [6].

In optical fibers, improvement in performance in environments with ionizing radiation due $t(1$ hydrogen treatment was first noted by 171. where it was observed that hydrogen permeation into the fiber cither prior to or following irradiation suppressed radiation-induced absorplion. Dramalic improvements were seen in the visible region

\footnotetext{
I Work performed under the nuspices of the IIS I Iepartment of I:nergy.
}

near the $2 \mathrm{eV}$ draw-induced defect in these demonstrations [8]. These and other papers have thoroughly shown that hydrogen can bind into various defects. Special attention has been given to fibers with extremely low. OH concentrations, since these fibers are frequently more sensitive to radiation than high-OH materials, and low-OH fibers are required for long wavelength communication applications $[9,10]$. Beneficiai effects of hydrogen have also been recently observed in measurements of UV transmission in optical fibers [11]. A complete review paper has been published [12].

The present work employed a variation of most previous hydrogen treatments, in that hydrogen was maintained within a high-OH fiber during $\mathrm{Co}^{60}$ pre-irradiation. Absorption centers created during this first irradiation were then available for reaction with the permeated hydrogen. The goal was to use hydrogen reactions to "heal" weaker bonds that were hroken dusing the preirradiation, such that subsequent irradiations would occur in fiber with fewer major defects and, ideally, demonstratc improved radiation resistance. (This treatment process is most similar to that used in [8] where the reported data focused on the $2 \mathrm{cV}$ visible band.) High-Oll core material was chosen for these tests since this material has usually, although not exclusively, demon. strated superior resistance to increases in attenuation caused by exposure 10 ioni-ing radiation, and further improved resistance remains essential for some applications.

Motivation for the present approach stems from two observations. Measurements of Co60.induced allenualion in high.()ll fibers have usually produced strongly non linear dependence between increased allen. uation and radiation dose. lior example, in ligg. 3 of $|13|$. wherein attenuation increases 
were studicd de.ing $10 \mathrm{krad}$ exposures, more than $90 \%$ of the radiation-induced attenuation was created with less than the first $10 \%$ of the total dose. In transient radiationinduced measurements, observations of the increased attenuation at early times, for example, in Fig. 4 of [14], measured on the basis of unit absorbed dose, demonstrate strong nonlinearities. In both these cuses, it can be speculated that the behavior could be explained by some class(cs) of pre-existing defect(s) in the drawn fiber that is casily damaged at low doses, but whose effects become much less significant at higher doses (perhaps as the number of pre-existing defect sites become saturated). If the number of pre-existing defects can be reduced through a combined radiation exposurc (to creats a site), and hydrogen exposure (to bind into the site), significant improvement in radiation resisiance should result.

\section{EXPERIMENTAL PROCEDURE}

Two different batches of test fiber were specially prepared for these measurements. For cach batch, a Fluosil [15] fluorosilicate clad preform with a high-OH Suprasil core was diawn at Polymicro Technologies, Inc. into a $100 \mu \mathrm{m}$ core diameter fiber. Clad diameter was $110 \mu \mathrm{m}$ and a thin polyimide buffer layer was applied, resulting in a final diameter of $125 \mu \mathrm{m}$. [This buffer layer has been shown in previous efforts $[14,16]$ to result in impreved radiation resistance.) Each batch of test samples was cut from a single le igth of optical fiber drawn from one preform.

In the first series of measurements, the fiber was prepared as described above. llowever, severe instabilities were noted in the measurements with that fiber. which were hypothesized 10 be traceable: 10 large and highly variable microbending losses (variations in a:tenuation) in the multi. layer test coils of fiber utilized in the radiation lests. The second batch of fiber was prepared as described abouc, but an actdilional acrylate buffer layer was a lded le; increase lice fiber diameter from $125 \mu \mathrm{ml}$ (1) 250 $\mu \mathrm{m}$, and reduce microlicnd sensitivity. This second batch demonstrated stable attenuation in subsequent lests.
Measurements with the first series of fibers demonstratid significant benefits to be realized from the simultaneous hydrogen concentration in the fiber and exposure to ionizing radiation. However, only data from the second batch of fiber will be reported in this paper.

The long single fiber was cut to lengths of $200 \mathrm{~m}$. Several of these shorter fibers were exposed to a 55 psi hydrogen atmosphere at $107^{\circ} \mathrm{C}$ for 100 hours. This time duration should be ample to guarantec a hydrogen concentration within the fiber close to equilibrium with the cxternal hydrogen environment. After hydroget permeation, the fibers were packed in dry ice to retard out-diffusion of the hydrogen and transported to a $\mathrm{Co}^{60}$ source. After warming to room temperature, some fibers were promptly exposed to $\mathrm{Co}^{50}$ doses at several dose levels. Details of fiber treatment are given in Table $I$. All fibers were then stored at room temperature for 7 days prior to subsequent tests. Most residual interstitial hydrogen gas, but not all, would have cscaped during this 7 day period. A quantitative measurement of residual hydrogen in the fibers during the final measurement was not available.

TABLE I

FIBER TREATMENT PARAMETERS

\begin{tabular}{|c|c|c|c|}
\hline Eiber "I & U2 Exposure & \multicolumn{2}{|c|}{$\mathrm{Co}^{60}$ pre-irracialion } \\
\hline 1 & no & & one \\
\hline 111 & ycs & & one \\
\hline 2 & no & 1 & krad \\
\hline 211 & yes & 1 & krad \\
\hline 3 & no & 10 & krad \\
\hline 311 & yes & 10 & krad \\
\hline 4 & no & 50 & krad \\
\hline 411 & yes & 50 & krad \\
\hline
\end{tabular}

Radiation induced allenuation was mea sured with a $\left(0^{\prime 00}\right.$ source under the condilions specified in the NATO Nuclear IEffects Task (iroup procedure $|17|$ A Laser Piecision AP.A20) Stabilized Fiber Optis: Light Source with an 8.50 ntII Al'Al8 laser oulput unit provided the illumination into " multimode 
pigtail. That pigtail was connected to the test fiber. The output of the test fiber was connected to a Hewlett Packard 81000JA Detector Head. The detector was coupled to a Hewlett Packard 8152A Optical / verage Power Meter whose output was measured with a Hewlett Packard 3457A Multimeter. The multimeter output were sampled on one second intervals under computer control and recorded. Per the specitication in the test procedure [17], input power to the test fiber was adjusted to be $1 \mu W$. Output powers from the test samples were about $0.5 \mu \mathrm{W}$.

Test fibers were wound on a $10 \mathrm{~cm}$ diameter test spool and placed $38 \mathrm{~cm}$ from a $13 \mathrm{kCi} \mathrm{Co}^{60}$ source. Source output was measured with an EG\&G, Inc. NIST-traceable 1 cc air ionization chamber whose output was corrected for pressure and temperature. Dose in rads was obtained using $33.7 \mathrm{cV} /$ ion pair in air and gamma ray attenuation coefficients for both $\mathrm{SiO}_{2}$ and air [18]. The resulting correction factor from Roentgen to $\operatorname{rad}\left(\mathrm{SiO}_{2}\right)$ was 0.869. [All doses in this paper are in units of $\operatorname{rad}\left(\mathrm{SiO}_{2}\right)$.] Dose at the center of the fiber bundle was $21.66 \mathrm{rad} / \mathrm{s}$ (130n $\mathrm{rad} / \mathrm{min}$ ) after correction for spool and fiber attenuation. Fibers were irradiated to a 10 krad total dose.

\section{DATA}

Altenuations are listed in Table II for several dose levels, including the final 10 krad level, and actual data follow in Fig. 1-4. Previous measurements [14] of similar fibers have frequently shown a peak in the radiation-induced attenuation at low dose (a few hundred rads) with an improvement (i.c., decrease) in altenuation at higher doses. That phenomenon was observed in some of the present measurements and this peak attenuation is denoted by $a_{p k}$ in Table II.

\section{IDSCUSSION ANII) (ONCLUSIONS}

In lig. 1, data from fibers 1 and 111 are inlerempared. If all lise hydrogen diffused into sample III had diffused back out, lliese Iwo ribers should have yiclded cquivalent performance. The significant difference demonstrates that out-diffusion has not been completed and that residual hydrogen is still present. It may be speculated that the improvement in performance of fiber $1 \mathrm{H}$ at late time is due to that residual hydrogen healing defects that were created during the irradiation. At early times, where fibers 1 and $1 \mathrm{H}$ are comparable, it is probable that the residual hydrogen has not yet had time to diffuse to the defect centers being created.

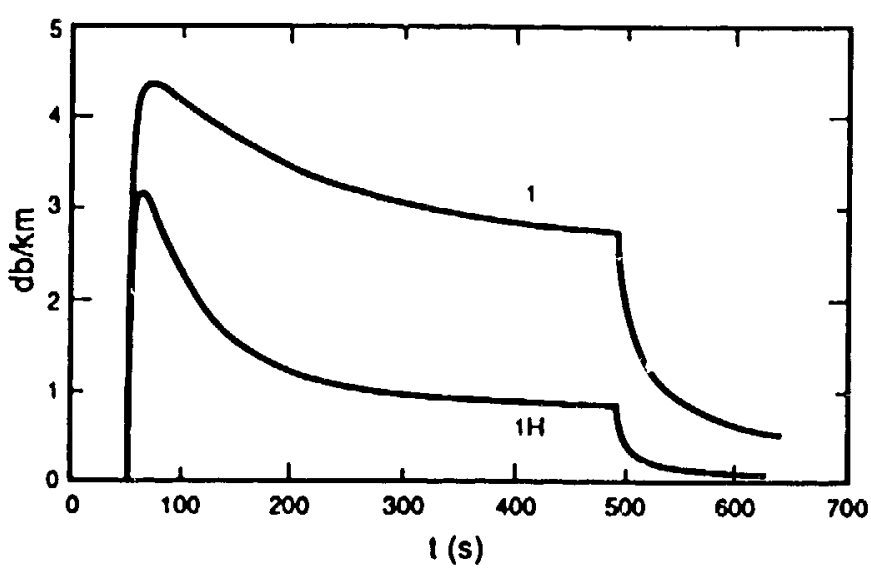

Fig. 1. Radiation-induced absorption for fibers 1 and $1 \mathrm{H}$. Performance of the control fiber (1) is similar to that observed for comparable fibers (PM2 and PM3) in [14] where apk of 4.23 and $2.91 \mathrm{db} / \mathrm{km}$ and autenuation at $10^{4} \mathrm{rad}\left(\mathrm{S}_{\mathrm{i}} \mathrm{O}_{2}\right)$ of 2.26 and $2.25 \mathrm{db} / \mathrm{km}$ were noted, respectively.

Table II

RADIATION-INDUCED ATTENUATION DATA $(\mathrm{db} / \mathrm{km})$

\begin{tabular}{|c|c|c|c|c|c|}
\hline \multirow[b]{2}{*}{ Eiber \# } & \multicolumn{4}{|c|}{ Cose $\left[\mathrm{rad}\left(\mathrm{SiO}_{2}\right)\right]$} & \multirow[b]{2}{*}{$A_{p k}$} \\
\hline & 100 & 200 & 500 & $10^{4}$ & \\
\hline 1 & 3.25 & 4.06 & 4.35 & 2.73 & 4.36 \\
\hline 111 & 2.51 & 3.09 & 2.99 & 0.83 & 3.17 \\
\hline 2. & 2.32 & 3.04 & 3.34 & 2.39 & $\therefore .35$ \\
\hline 211 & 0.73 & 0.85 & 0.88 & 0.74 & 0.87 \\
\hline 3 & 1.27 & 1.68 & 1.98 & 2.35 & - \\
\hline 311 & 0.57 & 0.67 & 0.70 & 0.64 & 0.70 \\
\hline 4 & 1.20 & 187 & 2.58 & 3.25 & - \\
\hline 411 & $0.4 ?$ & 0.55 & 0.63 & 0.01 & 0.63 \\
\hline
\end{tabular}

Pre-irradiation of optical fibers frequently leads (o) a somewhat improved 
performance in a subsequent radiation exposure, as noted in [14]. This could occur for several reasons. For example, radiation-induced annealing may be occurring as defects are effectively healed through relaxation of the neighboring lattice atoms into configurations resulting in stronger bonds. In these high-OH fibers, the radiation may itself be releasing hydrogen, which can diffuse to and bond into broken bonds. Other explanations may also be appropriate. For the first two pre-irradiation levels of 1 and $10 \mathrm{krad}$, significant improvement is noted in Fig. 2 where the four fibers, which were not exposed to hydrogen, are intercompared.

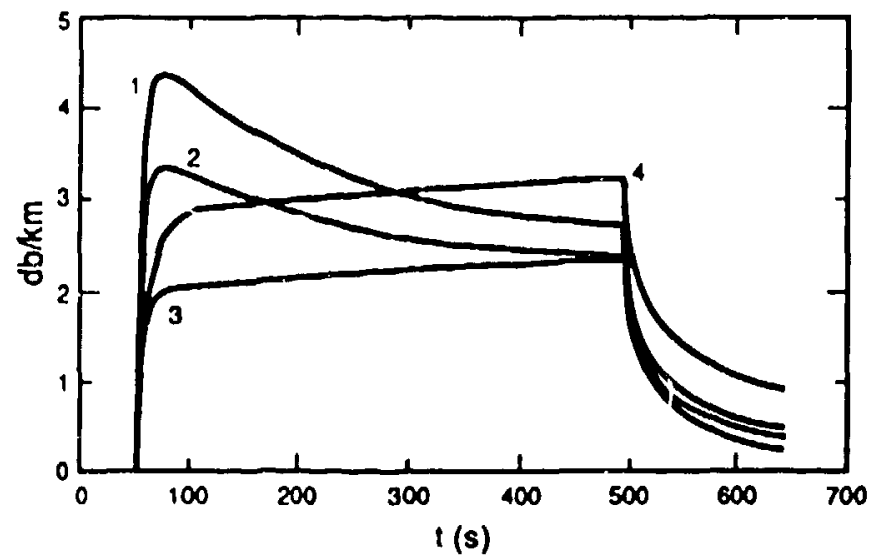

Fig. 2. Radiation-induced absorption for the control fiber (1) and the throe pre-irradialca fibers (2-4).

In Fig. 3, extremely dramatic improvement in radiation-induced attenuation is noted where the control fiber is compared to the three fibers that were pre-irradiated whilc significant levels of molecular hydrogen were within the fibers. This improvement is further clarified in Fig. 4 where the same four fibers are intercompared at carly times. Large ratios between treated and untreated samples are crident.

In fibers of this type, without pretreatment, about $90 \%$ of the rinal altenuation is realized before more than $5-10 \%$ of the dose is delivered. The original motivation for the current study was a hypothesis that the extremely rapid rise in attenuation of untrealed fibers at low doses may be due 10 a class of readily damaged pre-existing defects. It was hypothesized that the hydrogen gas

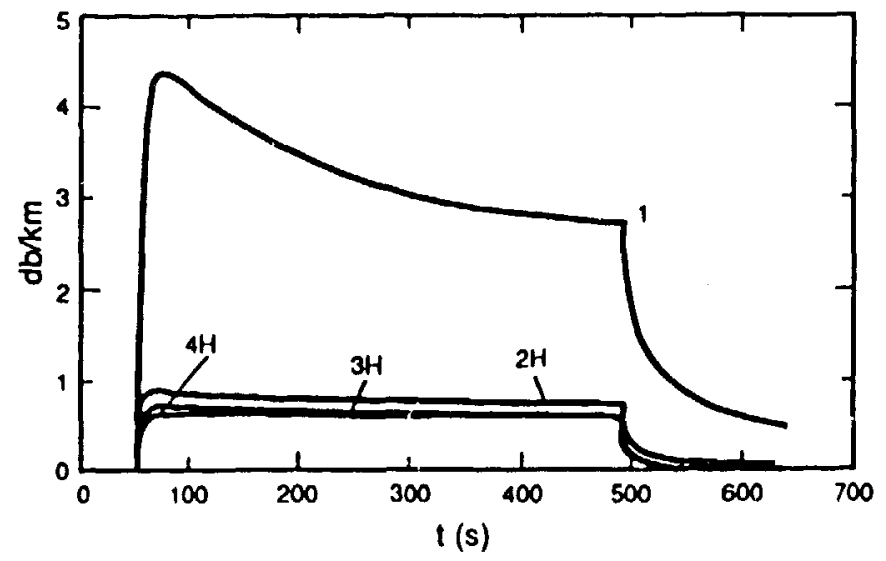

Fig. 3. Radiation-induced absorption for the control fiber (1) and the three fibers $(2 \mathrm{H}, 3 \mathrm{H}, 4 \mathrm{H})$, which were exposed to radiation while hydrogen was present, prior to the attenuation measurements shown here.

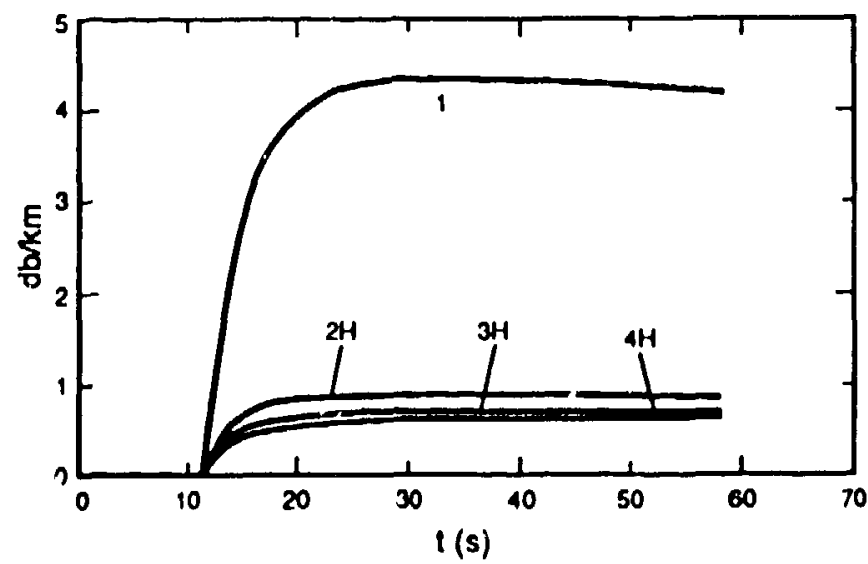

Fig. 4. Data of Fig. 3, repeated to illustrate hehavior at carly times (low doses).

might bind into those sites in the presence of radiation, thereby decreasing the damage probability for that site. If this had occurred, the fibers treated with hydrogen would not have displayed the rapid initial increase in attenuation, and ideally would have demonstrated a linear dependence of atienuation on dose. In the observed data. however, the attenuation observed in all the samples, whether hydrogen treated or not, was still very nonlinear.

Nevertheless, the hydrogen plus preirradiation treatment has demonstrated cxtremely beneficinl results, yielding about $8 x$ less attenuation at carly limes and rew 100) rad doses (cr. ligg. 4). Thus, some classes of 
defects have been partially (or totally) healed by the hydrogen treatment, but clearly not all them. Other choices of preirradiation conditions (higher doses, for example) need to be further examined.

Additional work is clearly required to optimize this process. The three pre-irradiation dose levels chosen herein suggest that still higher doses may be more beneficial. The stability of the hydrogen bound into the created defects needs to be studied, although it would be anticipated that this hydrogen should be very robustly bound into those sites. Additional studies should be made when a larger fraction of the hydrogen has diffused out of the fiber. Further studies could also explore hydrogen treatment of the fiber preform, before fibers are drawn, as was demonstrated to significantly improve UV performance of similar fibers [11]. Transient radiation-induced altenuation measurements need to be completed to see if the large differences noted herein, approaching a decade improvement in radiation-induced attenuation, can be duplicated under pulsed exposure conditions.

\section{ACKNOWLEDGEMENTS}

EG\&G, Inc. personnel (Las Vegas, NV), $R$. Head and $C$. Wilson operated and calibrated the $\mathrm{Co}^{60}$ source; B. Whitcomb, J. Kneidel, E. Pope, and J. Duran provided the instrumentation and assisted in data reduction. D. Mills of Los Alamos National Laboratory assisted in data reduction and $L$. Tabaka assisted in fiber operations.

\section{REFERENCES}

(1) S.P. Fiale, J.J. Schmidt, and D.M. Roy. "Irradiation lifrects in Glasses: Suppression by Synthesis under liigh Pressure llydrogen," Science vol. 156, pp. 1593.1594, 15: i7

121 J.I:. Shelby, "Kadiation liflects in Ilydrogen-Impreg. nated Vitrcous Silica," Jral. Appl. Phys. "ol. 50. pp. 37(1)2.3706, 1979.

[3] K. Nagasama, T. Todoriki, T. Pujii, Y. Ohki, and Y. llama. "The $1.52 \mathrm{\mu m}$ Absorption Band in Optical libers Induced by Hydrogen Treatment," Japanese Jral. Appl. Phys rol. 25, pp. 1.853.1.855, 1986,

(4) K. Mochizuti, Y. Namihira, II. Yamamoto, - Transmission Ioss Increase in (Optical liberes due (o)
Hydrogen Purmeation," Elec. Lelt. vol. 19. p. 743745, 1983.

[5] K. Mochizuki, Y. Namihira, M. Kuwazuru, and $M$. Nunokawa, "Influence of Ilydrogen on Optical Fiber Loss in Submarine Cables," IEEE Jrnl. Lightwave Tech. vol. LT-2, pp.802-806, 1984.

[6] KJ. Beales, D.M. Cooper, WJ. Duncan, and J.D. Rush, "Practical Barrier to Hydrogen Diffusion into Optical Fibres," Technical Digast-Conference on Optical Fiber Communication (New Orleans), postdeadline paper WI-5. January 1984.

[7] K. Nagasawa, Y. Hoshi, Y. Onki, and K. Yahagi, "Improvement of Radiation Resistance of Pure Silica Core Fibers by Hydrogen Treatment," Japanese Jrnl. Appl. Phys. vol. 24. pp. 1224-1228, 1985.

[8] K. Nagasawa, R. Tohmon, and $Y$. Ohki, "Cause of the Radiation-induced $2 \mathrm{eV}$ Absorption in Pure-Silica Core Fibers and Hydrogen-Treatment to Suppress the Absorption," Technical Digest-Fourth International Conference on Optical Fiber Sensors (Tokyo), pp. 335-338, 1986.

[9] K.-F. Klein, A. Muhlich, K. Worner, H. Henschel, O. Köhn. H.U. Schmid,. "Influence of $\mathrm{H}_{2}$ Treatment and Water Content on the Recovery Characteristics of Undoped Core Fibers after Pulsed and Continuous Irradiation," SPIE vol. 867, pp. 17-24, 1987.

[10] B.D. Evans, "The Role of Hydrogen as a Radiation Protection Agent at Low Temperature in a Low-Oll, Pure Silica Optical Fiber," IEEE Trans. Nucl. Sci. vol. 35. pp. $1215-1220,1988$.

[11] II. Fabian, U. Grzesik, K.-II: Worner, K.-F. Klein, "Optical Fibers for UV-Applications." to be published in SPIE wol. 1513, 1991.

[12] J. Stone. "Interactions of Hydrogen and Deuterium with Silica Optical Fibers: A Review," IEEE Jral. Lighiwave Tech. vol . LT-5. pp. 712-733, 1987.

[13] E.W. Taylor, E.J. Friebele, H. Henschel, R.II. West, J.A. Krinsky, and C.E. Barnes, "Interlaboratory Comparison of Radiation-Induced Attenuation in Optical Fibers. Part II: Steady-State Exposures," IEEE Irnl. Lighiwave Tech. vol. 8, pp. 967-976. 1990.

[14] P.B. L.yons, L.D. Looney, H. Henschel, O. K8hn, HI.U. Schmidt. K.-Fr. Klein. HI. Labian, M. Mills, G. Nelson, "Influence of Draw Conditions on UV Transmission and Radiation Sensitivity of an Op':cal Hiber," SPIE vol. 1174, pp. 2-19. 1990.

115] Fluosil is a registered trademark of Heracus Quarz.glas, Gimbll, Hanau, Germany.

[16] R.A. Greenwell, C.I:. Harnes, (i.W. Nelson, "The lifícets of Ionizing Padiation on Various Core/Clad Ratio Siep Index Pure Silica libers," SPIE vol. 807. pp.10.16. 1987.

[17] NATU Nuclear I:ffects Task Group, "Procedure for Mensuring Sleady Stale Camma Radiation-Induced Attenuation in Optical libers and Optical cables," l.os Alamos repoit number LA UR 90)-1901. 1990.

|| $8 \mid$ U. S. Department of Ileallh, liducution, and Welfare. Radiological Ileallh Ilandbook. 1970. 